\title{
PENGARUH LATIHAN PLYOMETRICS TERHADAP HASIL TOLAKAN START PADA OLAHRAGA RENANG
}

\author{
Aziz Rubiansyah', Agus Rusdiana', R. Boyke Mulyana' \\ ${ }^{1}$ Fakultas Pendidikan Olahraga Dan Kesehatan, \\ Universitas Pendidikan Indonesia.
}

Em@ il: azizrubiansyah@ rocketmail.com

\begin{abstract}
Abstrak
Tujuan dari penelitian ini adalah mengetahui pengaruh latihan plyometrics terhadap hasil tolakan start dalam olahraga renang terutama pada block time phase. Sampel diambil sebanyak delapan orang atlet putra dari UKM AQUATIK UPI dengan menggunakan teknik Purposive Sampling. Metode penelitian ini menggunakan penelitian kuantitatif dengan pendekatan eksperimental one group pretest posttest desingn. Pengambilan data dilakukan menggunakan Digital-Kamera sebanyak dua kali pada saat pretest dan pada saat postest. Test terdiri atas tiga jenis phase yaitu block time phase, flight time phase, dan glide time phase. Tahap yang diukur adalah teknik grab start meliputi data tolakan start terutama pada block time phase. Masing-masing tahap penilaian pada block time phase yaitu jarak tempuh, kecepatan rotasi sendi lutut, impuls, leg power, ground reaction force (GRF). Kemudian data berupa rekaman di input menggunakan software frame dias IV. Perhitungan statistik menggunakan SPSS dengan sub menu Independent Sample T-test. Uji hipotes is keseluruhan digabungkan dengan T-Score $\mathrm{t}=21,903, \mathrm{p}=0,000<0,05$ maka Ho ditolak, artinya Terdapat pengaruh yang nyata (signifikan) Setelah dilakukan analisis data diperoleh nilai $(\mathrm{p})<0,05$. Berdasarkan hasil tersebut penelitian ini menyimpulkan bahwa terdapat pengaruh latihan plyometrics terhadap hasil tolakan start dalam olahraga renang terutama pada block time phase.
\end{abstract}

Kata Kunci: plyometrics, tolakan start, grab start, olahraga renang, kecepatan rotasi sendi lutut

\section{PENDAHULUAN}

Renang merupakan cabang olahraga yang diperlombakan untuk putra dan putri, dimulai dari tingkat daerah, nasional, maupun internasional. Gaya renang yang diperlombakan adalah gaya bebas, gaya kupu-kupu, gaya punggung, dan gaya dada, pada dasarnya olahraga renang termasuk kedalam olahraga prestasi. Untuk memupuk suatu prestasi olahraga renang, baik tingkat nasional maupun internasional maka harus dimulai dengan mencari calon atlet berbakat dan kemudian dibina melalui latihan yang teratur, terarah, terencana serta berkesinambungan dan berkelanjutan. Berdasarkan Kristiyanto (2012:165), prestasi olahraga sebenarnya merupakan produk dari adanya akumulasi upaya sistematis berbagai faktor, yang perwujudannya harus diawasi melalui proses ilmiah. Ilmu pengetahuan dan teknologi keolahragaan merupakan sesuatu yang harus terimplikasikan secara baik dalam sebuah rangkaian usaha mencapai keunggulan dibidang olahraga tersebut.

Kristiyanto(2012:173) berpendapat pula bahwa perkembangan ilmu dan teknologi keolahragaan di Indonesia sebenarnya cukup pesat, namun kepesatan yang terjadi tidak sebanding dengan pemanfaatannya pada tataran praktis. Para pelatih olahraga dilapangan kurang familiar dengan bentuk-bentuk piranti lunak (software) maupun piranti keras (hardware) teknologi keolahragaan yang 
sebenarnya berguna untuk mengembangkan prestasi atlet secara efektif. Untuk membangun olahraga renang agar lebih baik kedepannya diperlukan rencana yang teratur dengan baik dengan tujuan yang jelas dan terarah.untuk membantu prestasi agar maksimal ada beberapa aspek yang di perlukan dalam membina olahraga renang diantaranya aspek fisik, aspek teknik, aspek taktik, dan latihan mental. (Harsono, 1988:100)

Dalam aspek teknik, hal pertama yang dilakukan oleh perenang sebelum perlombaan adalah melakukan awalan start dan hal ini seringkali kurang dicermatinya oleh para pelatih pada saat perlombaan. Orientasi utama para pelatih hanya pada latihan fisik semata, padahal ketika sebuah teknik start dicermati pentingnya sebuah power yang kuat dan cepat ketika menolak pada bok start ada beberapa macam teknik start yang sering dilakukan oleh perenang diantaranya; Racing Start, Swing Start, Grab Start, dan Tract Start. Badruzaman (2009:26) Dalam cabang olahraga renang waktu start memerlukan gerakan otot tungkai dan lengan dibutuhkan gerakan eksplosif, karena untuk melakukan gerakan tersebut memerlukan daya ledak otot yang maksimal. ketika gerakan start dilakukan dibutuhkan sebuah power yang kuat dan cepat selain itu memerlukan gerakan reaksi, ketika aba-aba datang perenang harus memiliki reaksi yang baik guna menghasilkan tolakan start yang optimal.

Start sangat menentukan keberhasilan seorang perenang mencapai prestasi yang di inginkan. Start adalah suatu teknik gerakan yang dilakukan menolak dengan cepat pada balok start pada permulaan perlombaan. Secara teoretis dan berdasarkan peraturan perlombaan, start dibagi menjadi dua yaitu start yang dilakukan di atas berdiri pada balok start dan start yang dilakukan di bawah menggantung pada balok start. Start yang dilakukan di atas balok start yaitu untuk gaya bebas, gaya dada, dan gaya kupu. Start yang dilakukan di bawah balok start dilakukan untuk gaya punggung. (Badruzaman, 2013:97)
Pada dasarnya dalam mekanika teknik start ada yang disebut dengan titik berat. Menurut Hidayat (1998:6) massa dari anggota tubuh yang bekerja sebagai gaya tahanan mempunyai titik pusat masa. Titik pusat masa tersebut disebut titik berat badan. Lebih jelasnya dipaparkan Hidayat (1998:6) titik berat adalah titik dimana gaya berat benda atau anggota tubuh itu bekerja. Dapat juga dikatakan bahwa titik berat adalah titik dimana gaya berat benda atau anggota tubuh itu bekerja. Dapat juga dikatakann bahwa titik berat adalah titik yang mewakili berat dari benda tubuh. Saat perenang melakukan tolakan start pada teknik grab start, titik berat harus melebihi titik tumpuan maka dengan sendirinya saat perenang melakukan tolakan start pada teknik grab start maka akan jatuh atau menolak dengan sendirinya.

Kecepatan sudut (angular velocity) melakukan tolakan pada teknik grab start dipengaruhi salah satunya kecepatan sudut sendi lutut dan sendi pinggul, merupakan gerak rotasi. Menurut Hidayat (1998:90) kecepatan dari gerakan melingkar ini disebut kecepatan rotasi, atau kecepatan sudut, atau kecepatan angular dan diberi lambang $₫$ (omega). Kalau lintasan yang ditempuh oleh gerak linier dinyatakan dengan jarak $\mathrm{S}$, maka lintasan yang ditempuh gerak angular dinyatakan dengan besar sudut $\Theta$ (theta).

$$
\omega=\Theta / t
$$

keterangan:

$$
\begin{aligned}
& \oplus=\text { Angular Velocity } \\
& \Theta=\text { Perubahan Sudut (deg) } \\
& \mathrm{t}=\text { waktu (time) }
\end{aligned}
$$

Hukum implus dan momentum, momentum ialah besarnya gaya dorong dari suatu benda, dapat dikatakan momentum adalah kekuatan gerak, jadi momentum dari suatu benda itu diperoleh bila benda tersebut dengan suatu kecepatan. (Hidayat, 1998:169). Bila seorang perenang yang melakukan start pada renang gaya bebas, mengayunkan lengannya ke depan ayunan lengan ini merupakan momentum ke depan. (hidayat, 1998:170) demikian pula perenang dalam melakukan grab start saat 
melakukan kekuatan ayunan tungkai saat menolak disebut impuls dan saat melayang ketika menolak disebut momentum. Menurut hidayat (1998:170) impuls dan momentum merupakan hubungan sebab akibat. Momentu yaitu hasil dari perkalian massa dan kecepatan, dan setiap perubahan dalam momentum adalah sebanding atau sama besarnya dangan impuls yang menghasilkannya (impuls $=\mathrm{m} . \mathrm{Vf}-\mathrm{m}$. Vi)

momentum merupakan besaran gerak yang bertambah atau berkurangnya dengan car menambah atau mengurangi massa atau kecepatannya.

$$
(I=\mathbf{F} \times \mathbf{t})=(\mathbf{M}=\mathbf{m} \times \mathbf{V})
$$

Keterangan:

$\mathrm{M}=$ momentum $(\mathrm{kg} \cdot \mathrm{m} / \mathrm{s})$

$\mathrm{I}=$ Impuls (N.s)

$\mathrm{M}=\operatorname{massa}(\mathrm{kg})$

$\mathrm{V}=$ velocity $(\mathrm{m} / \mathrm{s})$

$\mathrm{F}=$ Force (Newton)

$\mathrm{t}=$ Time $(\mathrm{sec})$

Ground reaction force (gaya dorong permukaan) Ground Reaction Force dapat disamakan dengan hukum Newton 3 yaitu setiap ada aksi terjadi reaksi yang besar, berlawanan arah dan bekerja pada satu garis lurus. (Hidayat, 1998:106). Berdasarkan hukum tersebut, ketika manusia berjalan, berlari, menolak pada saat start, setiap kali kaki menyentuh tanah, disanalah Ground Reaction Force terbentuk. Asas aksi sama dengan reaksi berlaku pada tumpuan yang kuat seperti saat melakukan tolakan pada teknik grab start, dapat disimpulkan untuk menghasilkan reaksi yang besar, perlu tumpuan yang kuat. Tumpuan yang kuat terjadi bila gaya geseknya (Friction) cukup besar.setiap aktivitas olahraga yang memerlukan gaya propulsive yang besar, harus mempunyai tahanan (Resistence) yang besar pula. (Hidayat, 1998:106)

Latihan plyometrics dalam cabang olahraga renang saat peranang melakukan teknik start, pada saat gerakan tersebut dilakukan membutuhkan otot tungkai dan lengan dibutuhkan gerakan yang eksplosif, pada saat teknik start para pelatih harus cermat bagaimana seorang perenang melakukan gerakan tersebut dilakukan. Dari analisa tersebut harus mempelajari bagaimana menemukan suatu metode yang sesuai dengan gerakan dan karakteristik yang diperlukan, yaitu gerakan yang membutuhkan daya ledak otot yang eksplosif. Seperti dikemukakan (Harsono, 1990: 2) selain dengan latihan beban latihan yang amat baik untuk membuat otot memiliki daya ledak yang hebat atau eksplosif adalah latihan yang disebut plyometric. Metode yang sesuai dengan karakteristik ini adalah dengan latihan plyometrics gerakangerakan yang dilakukan harus secara eksplosif sehingga komponen fisik power akan cepat ditingkatkan hal ini cocok untuk gerakan start pada perenang. Bentuk latihan plyometrics yang diterapkan dalam penelitian ini berupa bentuk latihan squat jump, knee-tuck jump.

Melihat prestasi olahraga di Indonesia masih kurang terutama dalam cabang olahraga renang, kurangnya teknologi olahraga renang mengakibatkan belum tercapainya hasil yang maksimal untuk mencapai sebuah prestasi yang membanggakan. perlu adanya orientasi baru dalam pengembagan prestasi olahraga khususnya renang. Salah satu yang menarik dengan mengaplikasikan IPTEK olahraga melalui riset, terkait dengan pemanfaatan ilmu pengetahuan dan teknologi.

Tujuan penelitian dalam penelitian ini adalah untuk mengetahui pengaruh latihan plyometrics terhadap hasil tolakan start dalam olahraga renang terutama pada block time phase. Tujuan kedua adalah untuk mengetahui seberapa besar pengaruh latihan plyometrics terhadap hasil tolakan start dalam olahraga renang terutama pada block time phase.

\section{METODE}

Metode penelitian ini menggunakan penelitian kuantitatif dengan pendekatan eksperimenta, one group pretest posttest desingn. Menggunakan quasi eksperimen karena dalam penelitian ini sulit mendapatkan kelompok kontrol sebagai kelompok pembanding. Namun 
demikian, metode dalam penelitian ini juga merupakan rangkaian kegiatan percobaan dengan tujuan untuk menyelidiki suatu hal atau masalah sehingga diperoleh hasil dari proses treatment yang dilakukan pada sampel penelitian. Penelitian ini juga bertujuan untuk mencari pengaruh latihan plyometrics (variabel independen) terhadap hasil tolakan start pada olahraga renang (variabel dependen).

Setiap variabel dalam penelitian ini terdapat beberapa indikator yang menjadi aspek penilaian. Adapun indikator dari variabel plyometrics (variabel independen) terdiri dari squat jump dan knee-tuck jump dan indikator tolakan start pada olahraga renang (Grab Start) sedangkan sebagai variabel dependen terdiri dari lima indikator yaitu jarak, kecepatan rotasi sendi lutut, impuls, leg power, dan ground reaction force.

Populasi dalam penelitian ini seluruh anggota UKM AQUATIK UPI yang aktif sebanyak 20 orang. Adapun teknik sampling yang digunakan dalam penelitian ini adalah Purposive Sampling, dimana purposive sampling merupakan sampel yang diambil sesuai dengan pertimbangan-pertimbangan tertentu (Sugiyono, 2009:85).

- Sampel diambil sebanyak delapan orang atlet putra dengan menggunakan teknik Purposive Sampling. dimana purposive sampling merupakan sampel yang diambil sesuai dengan pertimbangan-pertimbangan tertentu (Sugiyono, 2009:85).

Adapun pertimbangan-pertimbangan sampel yang diambil dalam penelitian ini adalah: a) Sebagai perenang pemula, b) Berusia antara 1822 tahun, c) Berjenis kelamin laki-laki, d) Memahami dasar-dasar dan teknik olahraga renang, e) Belum mempunyai power tungkai dan reaksi yang baik. Penelitian ini diberikan perlakuan selama 18 kali pertemuan.

Instrumen yang digunakan dalam penelitian ini; kamera digital (handy cam), Software Frame Dias IV (software analisis mekanika gerak), Secara umum pola input dan output data untuk Software Frame Dias digambarkan pada Gambar 1.1

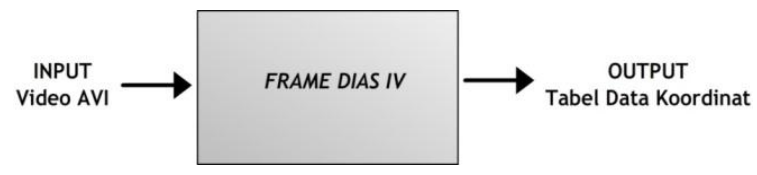

Gambar 1. Pola Input dan Output Software Frame Dias IV

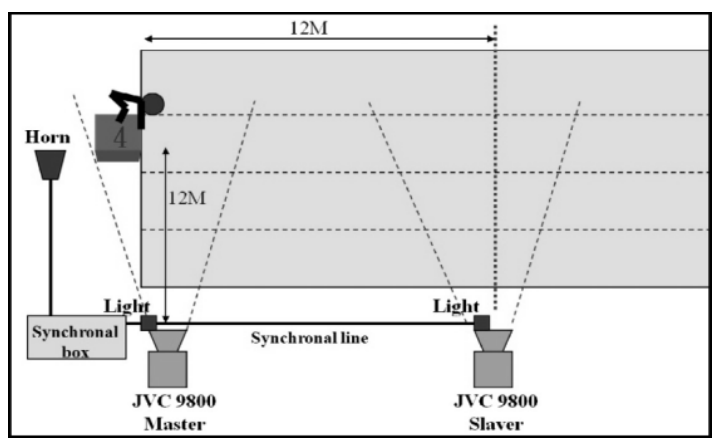

Gambar 2. Sistematika Pengambilan Data di Lapangan

Alat-Alat yang dibutuhkan Dalam Pengambilan Data yakni: (1) Dua buah tripod; (2) Dua buah video kamera; (3) Satu set kalibrasi; (4) Satu buah laptop; (5) Satu set sambungan listrik; (6) Satu buah meteran 50m; (7) Satu set Light Marker untuk penanda persendian.

\section{HASIL DAN PEMBAHASAN}

Hasil pengitungan tes awal nilai rata-rata dan simpangan baku tes tolakan start block time phase masing-masing tahap penilaian yaitu jarak, kecepatan rotasi sendi lutut, impuls, leg power, ground reaction force/GRF, dapat dilihat pada tabel 1.

Tabel 1. Perolehan Hasil Rata-rata Pretest

\begin{tabular}{l|cc|} 
& Rata-rata & Simpangan Baku \\
\hline Jarak & 15,2 & 0,8 \\
KRSL & 55,4 & 7,2 \\
Impuls & 346,2 & 136,1 \\
Leg Power & 1266,4 & 191,5 \\
GRF & 871,7 & 139,4
\end{tabular}

Berdasarkan tabel di atas dilihat dari hasil tes awal dapat dijabarkan bahwa rata-rata tes tolakan start (grab start) terutama block time phase dari setiap sampel, masing-masing item tes yaitu jarak 15,2 m, kecepatan rotasi sendi 
lutut 55,4 Deg/sec, impuls 346,2 N.Sec, leg power 1266,4 watts, ground reaction force 871,7 newton. Setelah diketahui hasil tes awal sampel diberi perlakuan berupa latihan plyometrics yaitu squat jump dan knee-tuck jump selama 18 kali pertemuan. Sesudah sampel diberi perlakuan berupa latihan plyometrics dilakukan tes kembali tolakan start (grab start) terutama block time phase dengan masing- masing item tes yang sama pada tes awal yaitu jarak, kecepatan rotasi sendi lutut, impuls, leg power, ground reaction force, untuk diketahui perbedaannya setelah diberikan perlakuan.

Hasil pengitungan tes akhir nilai rata-rata dan simpangan baku tes tolakan start block time phase, masing-masing tahap penilaian yaitu jarak, kecepatan rotasi sendi lutut, impuls, leg power, ground reaction force/GRF, dapat dilihat pada tabel 2.

Tabel 2. Perolehan Hasil Rata-rata Posttest

\begin{tabular}{l|cc|} 
& Rata-rata & Simpangan Baku \\
\hline Jarak & 19 & 0,9 \\
KRSL & 68 & 11,1 \\
Impuls & 438,2 & 133,6 \\
Leg Power & 1379,5 & 203,2 \\
GRF & 955,8 & 138
\end{tabular}

Berdasarkan tabel di atas dilihat dari hasil tes akhir dapat dijabarkan bahwa rata-rata tes tolakan start (grab start) terutama block time phase dari setiap sampel, masing-masing item tes yaitu jarak $19 \mathrm{~m}$, kecepatan rotasi sendi lutut 68,0 Deg/sec, impuls 438,2 N.Sec, leg power 1379,5 watts, ground reaction force 955,8 newton. Setelah tes awal dan tes akhir diketahui hasilnya, selanjutnya data diolah melalui penghitungan statistika.

Setelah uji homogenitas dan uji hipotesis, maka diperoleh hasil uji hipotesis keseluruhan (digabungkan dengan t-skor)

\begin{tabular}{|cc|c|c|}
\hline $\mathrm{T}$ & Sig. & Kepitusan & Kesimpulan \\
\hline 21,003 & 0,000 & $\mathrm{H}_{8}$ Ditolatk & Perbedoan Signifition \\
\hline
\end{tabular}

Terlihat bahwa nilai pada tabel nilat $\mathrm{t}=$ 21,903, $\mathrm{p}=0,000<0,05$ maka Ho ditolak, atau
Terdapat pengaruh yang nyata (signifikan) latihan plyometrics terhadap hasil tolakan start dalam olahraga renang terutama pada block time phase.

\section{KESIMPULAN}

Berdasarkan hasil pengolahan data, analisis data, dan pembahasan di bab IV mengenai pengaruh latihan plyometrics terhadap hasil tolakan start pada olahraga renang, maka dapat disimpulkan bahwa:

Terdapat pengaruh latihan plyometrics terhadap hasil tolakan start dalam olahraga renang, terutama pada block time phase. Hal ini terbukti latihan plyometrics berupa squat jump dan knee tuck jump dapat meningkatkan tolakan start, dalam hal ini grab start terutama pada block time phase dari setiap data tes yang meliputi item tes jarak, kecepatan rotasi sendi lutut, implus, leg power, dan ground reaction force. Sehingga kedepannya dalam proses latihan dapat diterapkan latihan plyometrics squat jump dan knee tuck jump. Hal ini dikarnakan memiliki kontribusi yang efektif pada teknik grab start terutama pada block time phase, sehingga dalam proses latihan ke depannya dapat meningkatkan prestasi dalam olahraga renang.

Besarnya pengaruh latihan plyometrics terhadap hasil tolakan start dalam olahraga renang terutama pada block time phase, ternyata dapat dibuktikan dari hasil data yang diolah melalui penghitungan statistika sehingga dapat disimpulkan bahwa pengaruh latihan plyometrics terhadap hasil tolakan start pada olahraga renang memiliki pengaruh yang sangat besar atau memiliki pengaruh nyata. Artinya bahwa latihan plyometrics berupa squat jump dan knee-tuck jump dapat meningkatkan tolakan start melalui teknik grab start terutama pada block time phase. Oleh karena itu Untuk meningkatkan prestasi dalam olahraga renang kedua teknik tersebut agar dilatih. 


\section{DAFTAR PUSTAKA}

Amin, N. (2013). "Sumbangan Power Otot Tungkai Panjang Tungkai Kekuatan Otot Perut Terhadap Grab Start". Dalam journal of sport sciences and fitness.(2), ISSN 2252-6528

Badruzaman, (2007). Modul Teori Renang I. Bandung: Universitas Pendidikan Indonesia

Badruzaman, (2009). Modul Teori Renang II. Bandung: Universitas Pendidikan Indonesia

Badruzaman, (2013). Renang Untuk Pemula Lanjutan, dan Penyempurnaan. Bandung: universitas pendidikan Indonesia

Harsono. (1988). Coaching dan Aspek-Aspek Psikologis dalam Coaching, Jakarta: C.V Tambak Kusumah

Hidayat, Imam. (1998). Biomekanika. Bandung: Ikip Bandung Press

Kristiyanto, Agus. (2012). Pembangunan Olahraga untuk Kesejahteraan Rakyat dan Kejayaan Bangsa. Yuma Pressindo

Sugiyono. (2009). Metode Penelitian Pendidikan. Bandung: Alfabeta 